\title{
An Assessment of the Climatic Characteristics and Their Impact on the Traffic Accidents in the City of Ramadi.
}

\author{
Dr. Mohanad abed Hammad \\ Dr. Ammeer Mohammed Khalaf \\ mohanadhammad@uoanbar.edu.iq \\ ed.amir.mohammad@uoanbar.edu.iq
}

Abd Ul RAzzaq Mohammed Jabbar

ed.abdulrazak.mohammed@uoanbar.edu.iq

\begin{abstract}
The facets of the climate have a great impact on the traffic of different means of transportation as long as bad weather conditions usually reduce the density of the transportation, especially on the land roads, while good conditions help to increase the use of the land roads.

The climatic characteristics have a direct impact on the occurrence of the traffic accidents for the increase in the amount of rain, the fog and the intensity of fog are all responsible factors for impeding traffic stream. This study aims at identifying the effect of the climatic characteristics on the traffic accidents in the Ramadi city through the climatic data and trying to find out the impact of each element on climatic ones on the traffic stream in the study area.

This study also aims at reducing the impact of the climate in the traffic accidents in Ramadi city via finding some treatments to reduce the impact of the climatic characteristics in the occurrence of traffic accidents.

The study comes up with that all the climate elements: rain, dust storms and fog have a direct effect on the occurrence of a number of accidents in the study area.
\end{abstract}

Article Received: 18 October 2020, Revised: 3 November 2020, Accepted: 24 December 2020

\section{Introduction}

According to a recently published World Health Organization (WHO) report on road safety, the annual traffic accidents affect nearly 50 million and kill up to 1.2 million individuals worldwide. The increase in the number of traffic accidents has crucial impacts represented by the loss of lives and physical disabilities as well as the losses of the public and private properties.

In most of the world countries, traffic controls are decided that are provided to the vehicle owners or through weather forecasts through various media outlets to inform the vehicle drivers of the best methods that can be used, especially in the winter season, where heavy rains, snowfall and frequent fogs are among the phenomena that lead to a decrease in the density of the road transportation to the half on some days comparing to the clear days free of bad weather phenomena.

Some studies indicate that most of the road transportation accidents occur on cloudy days and wet roads which lead to the slipping or colliding of the vehicles.
Among the weather phenomena that lead to traffic accidents are rain, snow accumulation, fog, dust storms besides the devastating tornadoes.

The main concern of the study is summarized in what is the role of the climatic characteristics in increasing the traffic accidents in Ramadi city?

The study hypothesis confirms that climate has a crucial role in disrupting the traffic stream and causing a number of accidents on the roads in city of Ramadi.

\section{- Area of the study:}

Ramadi is considered the main city in Anbar Governorate and represents an administrative center in the governorate with a very high population densities that attract many economic and service activities towards it.

The city of Ramadi enjoys a distinctive geographical location which is located on the latitude 33 north, with great importance via its connection with its neighboring regions that it represents an important transport node through the convergence of transport roads such as the 
highway and international roads represented by the number 10 and 12 international roads. Hence it is considered a gateway for transportation between the east and the western of Iraq. This location of the city results in the emergence of a continuous transport movement along the year.

Map 1 Ramadi City

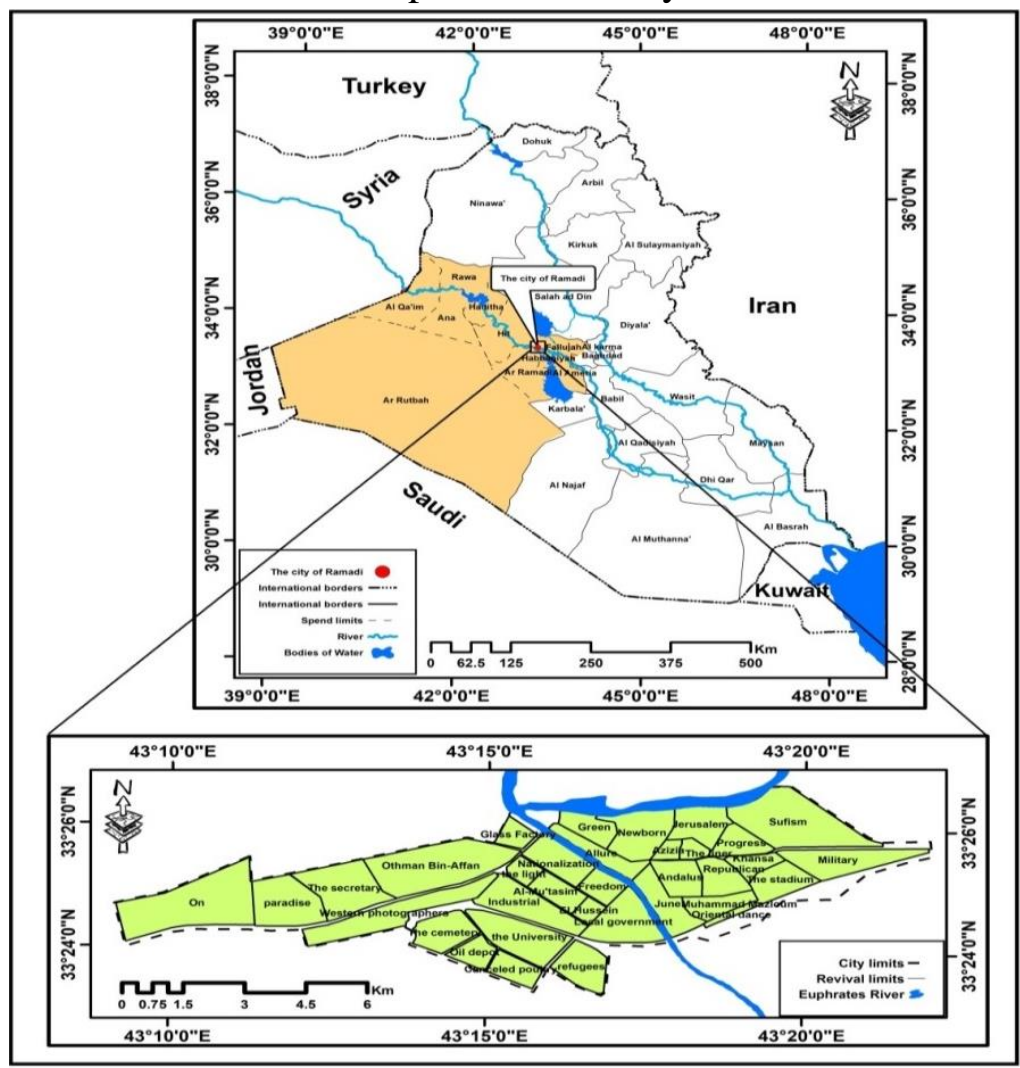

Source: Author's work

\section{- Network of roads cars in Ramadi city.}

The transportation roads have a great importance as they help in the growth and expansion of the cities and contribute to the constructing of the industrial complexes. Besides the main artery for the delivery of the foodstuff to the city and the transportation of workers who work in various service sectors.

Roads in Ramadi are classified into several types:

\section{1-Main roads}

These roads are responsible for connecting the parts of the city with one another, provide many facilities to accommodate large volumes of daily traffic. The main streets appear, in the city, of varying lengths, reaching $33.3 \mathrm{~km}$ in length, at a rate $(5 \%)$ of the total longest roads in the city. These roads distribute traffic towards districts without crossing, whenever possible, the main roads these environmental areas .

\section{2-Arterial roads}

These roads are distinguished by their large size with multiple lanes, linked to external roads and they turn into main roads when they enter the city for example the main round roads between the north and south of the study area. The total of the longest roads reached $60.4 \mathrm{~km}$, rating $9 \%$ of the total longest main roads.

Table 1, the length of roads in Ramadi

\begin{tabular}{|l|l|c|}
\hline Type of road & $\begin{array}{c}\text { Length } \\
\mathrm{km}\end{array}$ & $\%$ \\
\hline Arterial Road & 60.4 & $9 \%$ \\
\hline Main Road & 33.3 & $5 \%$ \\
\hline
\end{tabular}




\begin{tabular}{|l|l|c|}
\hline Secondary Road & 114.3 & $17 \%$ \\
\hline Local Road & 460 & $69 \%$ \\
\hline Total & 686.9 & $100 \%$ \\
\hline
\end{tabular}

Source: Ramadi City Municipality Directorate, Urban Planning, 2018

\section{3-Secondary roads}

These roads provide a service for traffic towards the heart of the city, as they connect the parts of the city as well as the commercial and entertainment services. These roads are called the community roads because they provide a service to local roads like the transporting of traffic to the main streets in the city or to local attraction centers such as the commercial centers and others . The total length of the longest roads was (114.3) $\mathrm{km}$ in Ramadi city, rating (17\%) of the total length of the longest roads of the city.

Figure 1 Lengths of roads in Ramadi city

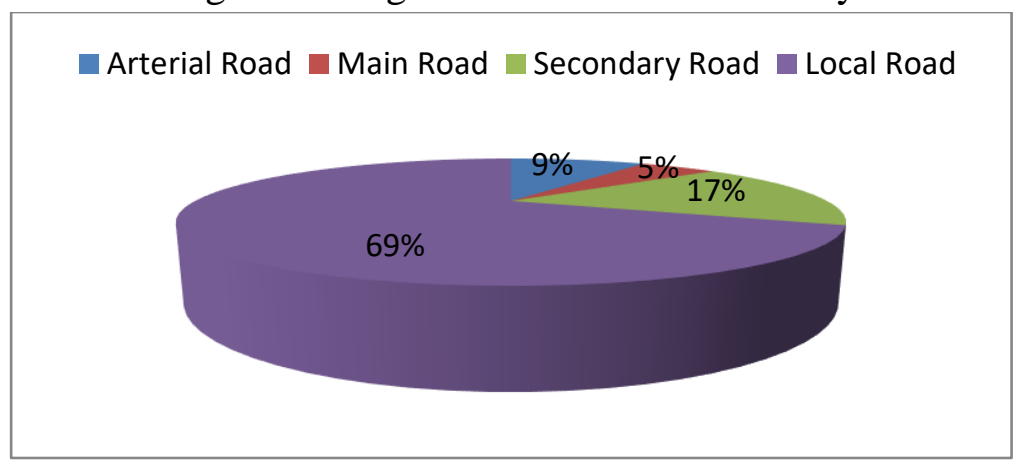

Source: based on Table 1

\section{4- Local roads}

They are represented by the streets of subresidential areas and within a residential district whose emergence is linked to the emergence of the residential district. Besides to the fact that it creates a kind of economic integration within the city, it is characterized by little traffic of up to
(900) vehicles per day or less, in addition to pedestrian traffic that can be transformed into Roads for the passage of vehicles at times of congestion and traffic jams on the main and secondary streets, with a total length of $46 \mathrm{~km}$, with a rate of $69 \%$ of the total city roads.

Map 2 Roads in Ramadi 2019

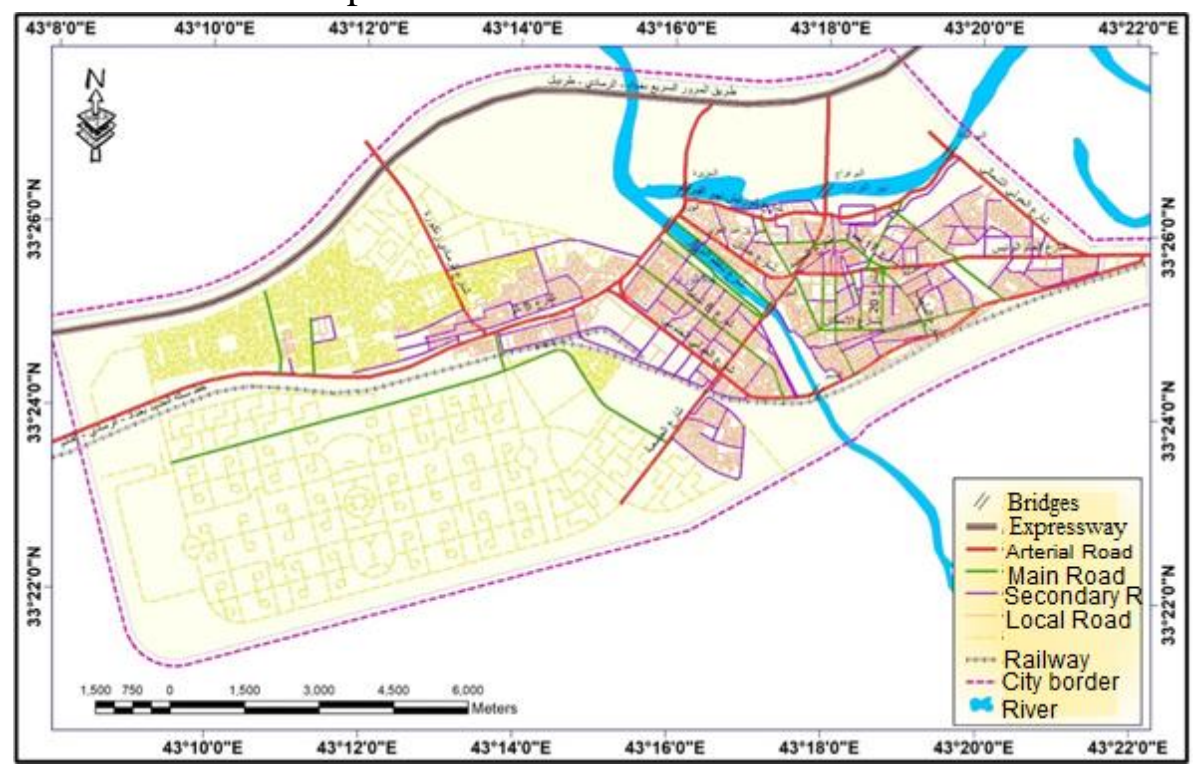


Source: Republic of Iraq, Ministry of Housing and Municipalities, Ramadi City Development Strategy for 2033.

-A geographical analysis of the climatic characteristics affecting traffic accidents in the city of Ramadi.

The climatic characteristics are characterized by a rapid change and have a direct impact on the various environmental elements, including the transporting movement. Dust storms, fog and rain, as well as solar radiation have a great affect on the increase in traffic accidents. We will clarify these characteristics in some detail in the area of study.

\section{1- Solar radiation:}

The amount of the solar radiation varies from one region to another on the surface of the earth according to the angle of the sun's fall, the length of the day and the clarity of the sky. Table No. 2 shows to us that the average solar radiation in the city of Ramadi is (551) $\mathrm{mw} / \mathrm{cm}$, where the highest value of solar radiation came in the month of July, when the average strength reached (742) $\mathrm{mw} / \mathrm{cm}$, due to the clearness of the sky, the lack of clouds and the length of the day as well.

Table 2: Monthly averages of climate characteristics in the city of Ramadi for the period (1999-

2019)

\begin{tabular}{|c|c|c|c|c|c|c|c|c|c|c|c|c|c|}
\hline $\begin{array}{c}\text { Climate } \\
\text { element } \\
\text { s }\end{array}$ & Jan & $\begin{array}{r}\mathrm{Fe} \\
\mathrm{b}\end{array}$ & $\begin{array}{r}\mathrm{Ma} \\
\mathrm{r}\end{array}$ & $\begin{array}{r}\text { Ap } \\
r\end{array}$ & $\begin{array}{r}\mathrm{Ma} \\
\mathrm{y}\end{array}$ & Jun & Jul & $\begin{array}{r}\mathrm{Au} \\
\mathrm{g}\end{array}$ & $\begin{array}{r}\mathrm{Se} \\
\mathrm{p}\end{array}$ & $\begin{array}{r}\mathrm{Oc} \\
\mathrm{t}\end{array}$ & $\begin{array}{r}\text { No } \\
\mathrm{V}\end{array}$ & $\begin{array}{r}\text { De } \\
\mathrm{c}\end{array}$ & $\begin{array}{r}\text { Avera } \\
\text { ge }\end{array}$ \\
\hline $\begin{array}{c}\text { Solar } \\
\text { radiatio } \\
\mathrm{n} \\
\mathrm{mw} / \mathrm{cm}\end{array}$ & $\begin{array}{c}34 \\
5\end{array}$ & $\begin{array}{c}34 \\
9\end{array}$ & $\begin{array}{c}46 \\
5\end{array}$ & $\begin{array}{c}54 \\
0\end{array}$ & $\begin{array}{c}73 \\
0\end{array}$ & $\begin{array}{c}74 \\
0\end{array}$ & $\begin{array}{c}74 \\
2\end{array}$ & $\begin{array}{c}66 \\
5\end{array}$ & $\begin{array}{c}57 \\
0\end{array}$ & $\begin{array}{c}43 \\
0\end{array}$ & $\begin{array}{c}39 \\
0\end{array}$ & $\begin{array}{c}35 \\
0\end{array}$ & 551,2 \\
\hline $\begin{array}{c}\operatorname{Rain}(\mathrm{m} \\
\mathrm{m})\end{array}$ & 22 & $\begin{array}{c}16 \\
8\end{array}$ & $\begin{array}{c}11, \\
5\end{array}$ & 14 & 4,9 & 0,1 & 0 & 0 & 0,4 & 7,8 & $\begin{array}{c}16 \\
8\end{array}$ & $\begin{array}{c}15 \\
5\end{array}$ & 109,8 \\
\hline Fog & 5 & 1 & 1 & - & - & - & - & - & - & - & 2 & 5 & 2,8 \\
\hline $\begin{array}{c}\text { Dust } \\
\text { storms }\end{array}$ & 0,2 & 0,3 & 0,5 & 0,7 & 1,5 & 1 & 0,7 & 0,5 & 0,3 & 0,3 & 0,1 & 0,1 & 0,5 \\
\hline
\end{tabular}

Source: Republic of Iraq, General Meteorological Authority, Climate Dep, 2019.

The solar radiation has an effect on the transport movement in decreasing the driver's range of vision and the ability to control the car. It also has an affect of the radiation on the road through the melting of the upper layer of the road, the occurrence of ripples in the road and the raising of the temperature of the car parts.

\section{2- Rain}

Rainfall is concentrated in the city of Ramadi in winter season, while the rain falls less in spring and autumn seasons and is diminished in summer. It is clear from table no. 2 that the highest rate of rain falls is in the month of January with an average of $22 \mathrm{~mm}$. The total annual rainfall in the city of Ramadi rated $(109.8) \mathrm{mm}$. The rate of rain decreases in spring gradually due to the lack of the tropical depressions in the study area.

The rain directly causes traffic accidents as it contributes to damage and destroy the roads and bridges resulted in the traffic disruption.

\section{3- Fog}

Fog has a great impact on the transportation in the city of Ramadi, where the highest rate of its occurrence in the study area is between the months of December and January according to the data of Table No. 2. It's effects are seen in the 
lack of visibility as it reaches several meters results in multiple accidents.

Fog has a great impact on transport movement that it's effect appears in increasing traffic congestion and, eventually, causes traffic accidents.

\section{4- Dust storms}

Recently, the city of Ramadi has been exposed to a lot of dust storms which cause a lack of visibility due to the moving sand in the air. According to the data of Table No. 2, the rate of these storms in the study area was 0.5 , with the highest occurrence recorded in the months of April, May and June due to the lack of rain.

Storms occur in desert and semi-desert areas and have the ability to erode the soil and move it to remote areas. The city of Ramadi is exposed to recurrence of these storms because of the surrounding desert environment. Dust storms disrupt road traffic and cause major traffic accidents as a result of sand that is gathered on the roads.

\section{-The Effect of the Climatic Characteristics on} Traffic Accidents in the City of Ramadi.

Traffic accidents are considered the most dangerous problems facing societies and have negative effects on the lives of many people every year. The studies indicate that traffic accidents are the third class in the classifying the causes of death. The casualties resulting from traffic accidents are very large including the casualties in the lives and properties.

The characteristics of the climate have a great impact on traffic in the city of Ramadi where car accidents increase due to the raising levels of fog and lack of visibility, heavy rains, high temperatures, as well as dust storms.

The climatic conditions affect the driver's abilities in terms of the focus and the range of vision. They also have an affect on the car in controlling, sliding and collision with the effect of these conditions on roads by destroying bridges and cracks in the roads.

Hence there should be an effect of these characteristics on the rate of traffic accidents in the city of Ramadi through Table No. 3 showing that the total number of accidents during the 10year study period reached to 1567 accidents, the least of which was in 2016 with 83 accidents, while in 2019 the most incidents were recorded with 377 accidents, while in 2014 and 2015 no incidents were recorded due to the fall of Ramadi city center at the hands of the terrorists.

Table 3: Traffic accidents in the city of Ramadi for the period 2009-2019

\begin{tabular}{|r|r|r|r|r|r|}
\hline Year & Accident & Radiation & Rain & Fog & Storms \\
\hline 2009 & 114 & 9 & 12 & 15 & 5 \\
\hline 2010 & 137 & 4 & 9 & 11 & 10 \\
\hline 2011 & 120 & 6 & 11 & 9 & 13 \\
\hline 2012 & 130 & 5 & 17 & 12 & 12 \\
\hline 2013 & 143 & 7 & 12 & 13 & 8 \\
\hline 2014 & - & - & - & - & - \\
\hline 2015 & - & - & - & - & - \\
\hline 2016 & 83 & 2 & 11 & 6 & 5 \\
\hline 2017 & 210 & - & 14 & 11 & 7 \\
\hline 2018 & 253 & 4 & 11 & 8 & 3 \\
\hline 2019 & 377 & 2 & 13 & 10 & - \\
\hline \multirow{2}{*}{ Total } & 1567 & 39 & 110 & 95 & 63 \\
\cline { 2 - 6 } & & $2.4 \%$ & $7 \%$ & $\% 6$ & $4 \%$ \\
\hline
\end{tabular}

Source: Traffic Directorate, Anbar Governorate, statistics, traffic accident data. 
Figure 2Traffic accidents in the city of Ramadi for the period 2009-2019

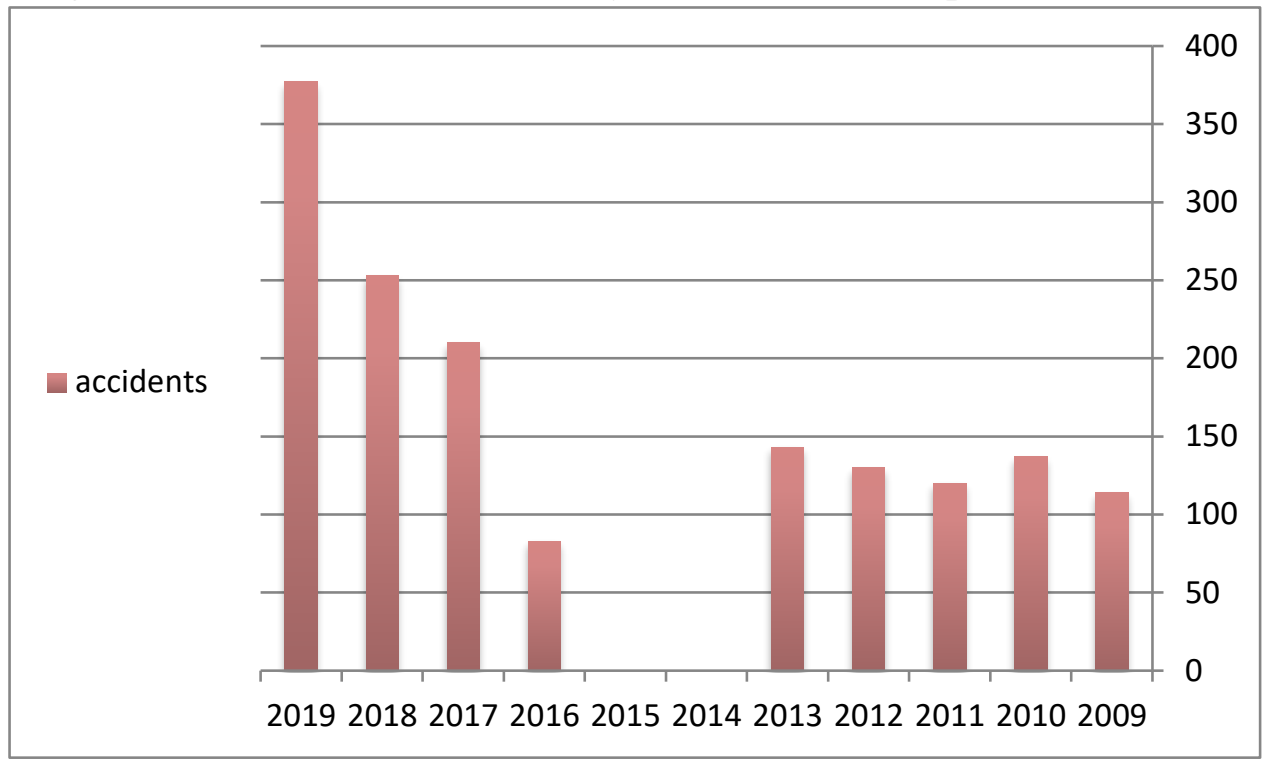

Source: based on Table 1

We, when distributed the accidents in detail, notice that accidents occurred due to the strength of solar radiation during ten years from 2009 to 2019, 39 accidents were recorded with a percentage of $2.4 \%$, which is the lowest percentage compared to other climatic elements.
2009 recorded the highest value of accidents that reached 9 accidents, while 2016 and 2019 recorded the lowest number of 2 accidents each. Figure 3 Impact of the Climatic Characteristics on Traffic Accidents in the City of Ramadi.

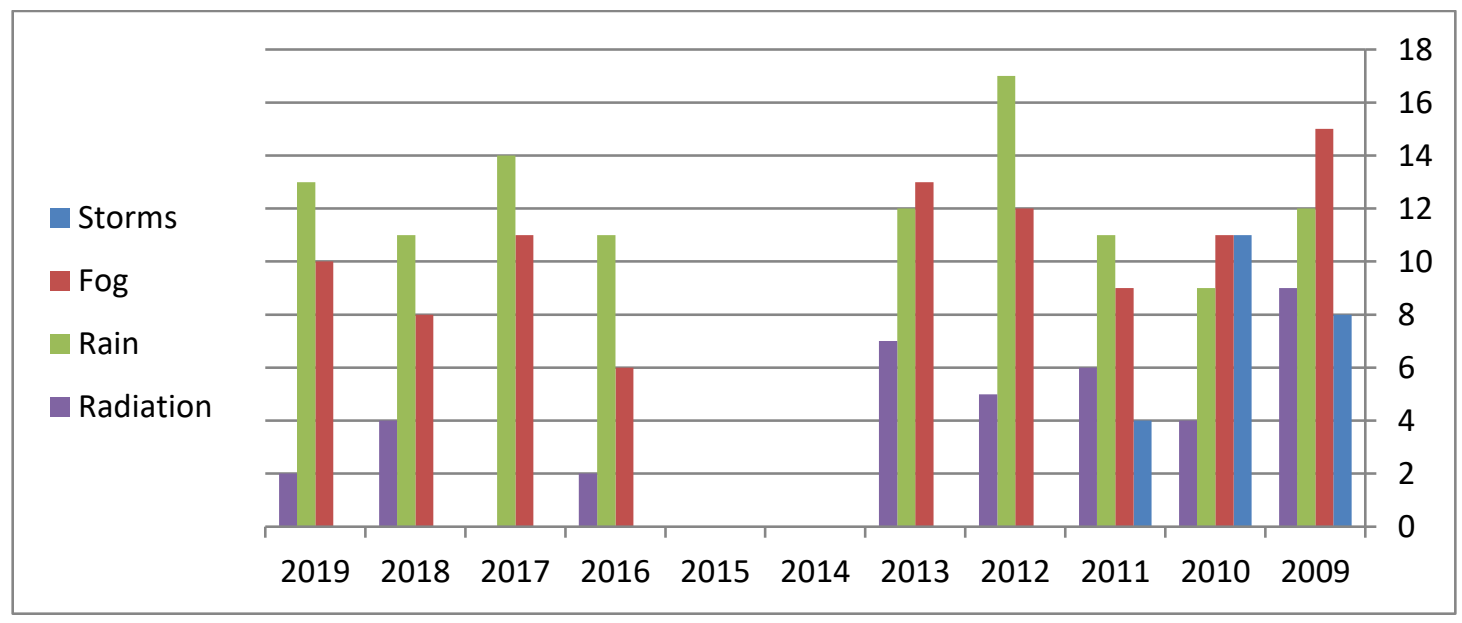

Source: based on Table 1

Concerning the number of accidents that were recorded due to rain, they were 110 accidents, with a percentage of $7 \%$ of the total number of accidents recorded due to climatic conditions which is the highest percentage compared to the rest of the other elements, that 12 accidents were recorded in 2009, whereas 13 traffic accidents were recorded in 2019 due to the erosion of some arch bridges, road blocks and the shortage of visibility for vehicle drivers.
As far as fog is concerned, it is crucially related to the lack of visibility of the driving range, 95 accidents were recorded during the study period, the lowest of which was in 2016 with 6 accidents, while in 2019, 10 traffic accidents were recorded in the study area.

The dust storms have their effect as well that 63 accidents were recorded during the study period that $4 \%$ of the total accidents that occurred due to the formerly limited climatic elements that 2011 
and 2012 have recorded the highest accidents with 13 and 12 accidents respectively.

The impact of dust storms is made clear by the accumulation of sand on the roads resulted in reducing the movement and the risk of the accidents. As they blow, more congestion and less movement occurs and the lack of visibility on the roads as well.
It is evident from the above that the total accidents that were due to climatic conditions are 307 constituted $20 \%$ of the total accidents. The rest of the accidents resulted from negligence, recklessness and speed over the average besides other reasons. There are other accidents that occurred due to climatic conditions that were not observed and documented by the Traffic Directorate of Anbar.

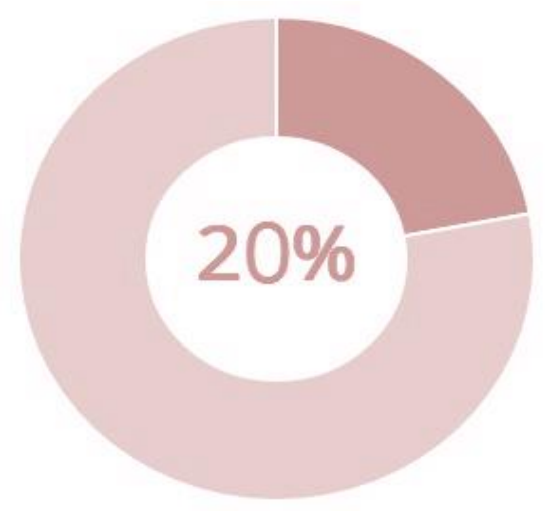

We conclude, from this research, that the climatic characteristics have a profound role in increasing the traffic accidents in the city of Ramadi. The fog phenomenon has an effect on traffic accidents through its role in the reduced visibility when heavy fog occurs which leads to an increase in accidents between vehicles. Fog causes cars to slow down on the roads resulting in a large gathering of cars and this leads to an increase in collisions accidents between them.

The heavy rainfall in the winter months causes accidents for vehicles to slip on the roads heavy rainfall leads to a reduced visibility.

Besides the power of solar radiation in the summer months, which directly affects traffic accidents through the extent of vision and the ability to control the car, especially at noon time, it affects the extent of vision and the loss of visual acuity the thing that poses a great risk and causes traffic accidents. Concerning the phenomenon of dust storms, which cause economic and human losses, therefore, it is necessary to tackle the disadvantages caused by the climatic characteristics to reduce these accidents on transportation roads in the city of Ramadi.

\section{Recommendations}

To reduce the impact of the climatic characteristics on the problem of traffic accidents that occur in all countries of the world, it is compulsory to decide some solutions and proposals that would help to reduce these accidents in the city of Ramadi:

-constructing multi-stations that monitor surface air movements and the layers of the atmosphere in order to analyze the climatic condition of the study area.

-The necessity to develop a general and comprehensive plan to raise the awareness of the dangers of traffic accidents and the resulting consequences to raise awareness of these risks in order to reduce the human and material losses.

-To keep Working on providing the roads with sewage networks to drain rain and torrential water in order to reduce their impact on the occurrence of traffic accidents and establishing resting places 
beside roads to stop vehicles in the time of rain, hail, fog and dust storms.

-Taking advantage of modern technologies to make the road safer and more adaptive to changing climatic conditions and the needs of road users too.

-Planting fast-growing trees next to the roads, with the aim of reducing the impact of dust storms on transport roads.

-Working on stabilizing the soil with chemical stabilizers and reducing the erosion process that occurs to the upper layer of the earth's surface during wind blowing. Additionally, the soil can be fixed with plastic nets that help reduce the erosion process and plant some shrubs and a pre- asphalt layer can also be sprayed for unpaved roads to reduce the impact of sand hills.

- Supplying the roads with active lights that in case of the occurrence of fog and dust storms, they will increase the visibility of the driver on the road.

\section{References}

[1] Stiers Brijs, Elke Hermans, The Impact of Weather Conditions on Road Safety Investigated on an Hourly Basis.2007.

[2] Adriaan Perrels, Athanasios Votsis, Weather Conditions, Weather Information and Car Crashes.2015.

[3] Ministry of Planning, Central Bureau of Statistics, land transport data for the period 2015-2019.

[4] Mahdi Qasim, Traffic and Traffic Rules on the Main Road, 2nd Edition, Baghdad 1982, pg. 38 .

[5] Ahmed Salim, Road Accidents, Their Causes and Methods of Prevention, Security and Life Journal, Riyadh, Issue 304,2014.

[6] Traffic Directorate, Anbar Governorate, statistics, traffic accident data.

[7] Mahmoud Ismail Muhammad, The Planning Features of the Urban Transportation System in the City of Falluja and a Test in the Efficiency of the System, Ph.D. dissertation (unpublished), Higher
Institute of Urban and Regional Planning for Postgraduate Studies, University of Baghdad, 2011., p. 35.

[8] Zain Al-Abidin Ali Safar, The Urban Planning (General Introduction), Dar AlKutub Al-Watanniyah (National Books House), Benghazi, 2004., p.57. 